\title{
Preventing Increased Air Pollution in Pennsylvania's Environmental Justice Communities
}

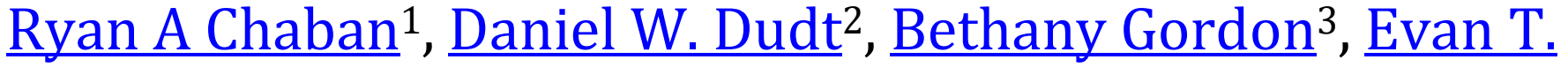 Ostrowski ${ }^{4}$}

${ }^{1}$ William \& Mary, Department of Physics, Williamsburg, VA

2Princeton University, Department of Mechanical and Aerospace Engineering, Princeton, NJ

${ }^{3}$ University of Virginia, Department of Engineering Systems and Environment, Charlottesville, VA

${ }^{4}$ Princeton University, Department of Chemical and Biological Engineering, Princeton, NJ

https://doi.org/10.38126/ISPG180407

Corresponding author: bmg6bt@virginia.edu

Keywords: environmental justice; air pollution; health disparities; climate policy; cap-and-trade; RGGI;

Pennsylvania

Executive Summary: Air pollutants are known to cause serious health impacts, and historically marginalized groups are disproportionately exposed to these risks. Other hazardous pollutants often accompany carbon dioxide emissions during fossil fuel combustion, and therefore reductions in greenhouse gas emissions from climate policy can also improve air quality. However, although these policies may reduce pollution overall, existing programs have often increased local emissions levels - particularly in the most overburdened neighborhoods. The adverse health effects caused by a redistribution of emissions must be considered as Pennsylvania plans to join the Regional Greenhouse Gas Initiative. We recommend the Department of Environmental Protection include an annual impact assessment of their cap-and-trade program on vulnerable communities using both the available carbon dioxide emissions data and additional local air quality measurements.

\section{Statement of issue}

i. Air pollution is particularly harmful to Environmental Justice communities

Pennsylvania's long history of using coal and natural gas for power generation has not only contributed to carbon dioxide $\left(\mathrm{CO}_{2}\right)$ pollution but has also expelled significant amounts of other pollutants (Clean Air Council, n.d.). These pollutants include $\mathrm{NO}_{\mathrm{x}}, \mathrm{SO}_{\mathrm{x}}$, VOCs, $\mathrm{PM}_{2.5}$, and air toxics ${ }^{1}$, and are known to contribute to adverse health effects (Clean Air Council, n.d.; Abelsohn and Stieb 2011; Wellbery 2017). Sources of air pollution are often located in resource-constrained and racially segregated areas, causing disproportionate health effects for marginalized groups ("Tracking and Evaluation of
Benefits and Impacts of Greenhouse Gas Limits in Disadvantaged Communities: Initial Report" 2017; California EPA 2017; Cushing et al. 2018; "Cap and Trade: More Pollution for the Poor and People of Color" 2019; FWW 2021; Miranda et al. 2011). These communities that face disproportionate exposure and increased vulnerability to environmental harms, including air pollution, are called overburdened communities or Environmental Justice (EJ) communities (US EPA 2016). Their well-being, in the context of new Pennsylvania (PA) climate regulations, is the focus of this analysis.

The negative health impacts of air pollution exposure can manifest more severely in individuals who are vulnerable due to extrinsic factors, such as ethnicity

${ }^{1} \mathrm{NO}_{\mathrm{x}}$ (Nitrous Oxides), $\mathrm{SO}_{\mathrm{x}}$ (Sulfur Oxides), VOC (Volatile Organic Compounds), $\mathrm{PM}_{2.5}$ (Particulate Matter $2.5 \mu \mathrm{m}$ ) 
or socioeconomic status (Ostro et al. 2006; Solomon et al. 2012). For example, these vulnerable groups may have less access to preventative healthcare, to fresh food, and to residences located away from major emitters (Tung et al. 2017). As a result, overburdened communities experience short-term (exacerbation of pre-existing respiratory and cardiovascular conditions) and long-term (development of new respiratory and cardiovascular disease, harm to fetal development, and increased mortality) health impacts of air pollution (Abelsohn and Stieb 2011; Smith et al. 2013; Wellbery 2017; Backes et al. 2013). These underlying conditions are also co-morbidities of the current COVID-19 pandemic, putting additional strain on these communities (Wu et al. 2020). Even within regulatory limits, several of the air pollutants responsible for these negative health effects can have a quantifiable impact (Di et al. 2017). As these pollutants correlate with $\mathrm{CO}_{2}$ emissions, it can be beneficial to address EJ air pollution concerns simultaneously with climate regulations targeting greenhouse gases (Cushing et al. 2018; Ostro et al. 2006; Burney 2020).

As Pennsylvania moves to enact a $\mathrm{CO}_{2}$ Budget Trading Program and join the Regional Greenhouse Gas Initiative (RGGI), the state should consider strengthening the EJ considerations in the bill. Some states who already participate in RGGI have needed to take post-factum action to address an uneven air pollution reduction that has disadvantaged EJ communities. In the following sections, we discuss the implications of an inequitable cap-and-trade system, the current status of the rulemaking in question, and our recommendations for how to move forward in a just way.

\section{ii. Cap-and-trade systems could exacerbate disparities in air pollution exposure}

Cap-and-trade systems, such as RGGI, are a marketbased tool for reducing anthropogenic sources of greenhouse gases in a particular region by setting a limit on $\mathrm{CO}_{2}$ emissions and requiring emitters within that region to purchase an allowance for every unit of $\mathrm{CO}_{2}$ that they emit. Allowances are either bought at regular auctions or traded between regulated facilities. By design, the total $\mathrm{CO}_{2}$ emissions in a capand-trade region should decline with time, as was observed in the current RGGI states (RGGI 2019) and California (CA) (CARB 2019), which has its own capand-trade system. However, the redistribution of emissions in a cap-and-trade region can lead to winners and losers at the local level. In fact, several studies on both the RGGI (Chan and Morrow 2019; FWW 2021; McKeown 2020) and CA (Cushing et al. 2018) cap-and-trade systems identified that emissions of $\mathrm{CO}_{2}$ and its co-pollutants increased from many facilities near EJ communities after the introduction of the cap-and-trade system (Figure 1). We note that the literature on the EJ consequences of CA's cap-and-trade system is mixed, with other reports showing positive outcomes in the state (Hernandez-Cortes and Meng 2020) or being inconclusive (California EPA 2017).

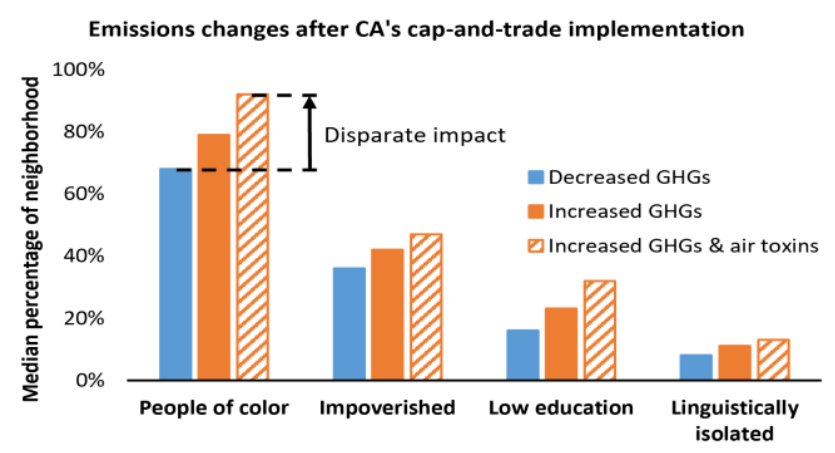

Figure 1: Correlation between demographics and emissions changes after the implementation of California's cap-and-trade system. Data is from reference (Cushing et al. 2018) Table 3 on neighborhoods within 2.5 miles of a regulated facility. (GHGs = greenhouse gases)

Existing regulations and programs of the United States Environmental Protection Agency (EPA) are unlikely to mitigate disparate impacts resulting from a cap-and-trade system. As mandated by the Clean Air Act, the EPA regulates air quality across the country by setting national ambient air quality standards for criteria pollutants and monitoring pollution levels at state-operated air quality testing stations (CFR 40.50). However, the relatively low spatial distribution of air quality monitoring stations does not effectively detect local "hot spots" (Fowlie et al. 2019) of air pollution and can lead to underregulation or over-regulation of certain regions by the EPA (Hsiang et al. 2019; Fowlie et al. 2020; Carlson 2018). In PA, which has sixty-five total air monitoring stations operating in thirty-eight of sixtyseven counties (Wolf and McDonnell 2020), local pollution hot spots potentially generated after capand-trade implementation might not be detected nor trigger a regulatory response by the EPA. Local testing and community monitoring of air quality can be crucial to filling in this missing data (Solomon et al. 2012; Fowlie et al. 2020; Snyder et al. 2013). 
The EPA is actively working towards improving EJ outcomes (EPA 2021) and continues to fund innovative projects to investigate creative solutions to state and tribal pollution issues (US EPA ORD 2020a). For example, the EPA is partnering with the New Jersey Department of Environmental Protection to study the effectiveness of a low-cost air sensor network monitored by citizen scientists for detection of air pollution hot spots (US EPA ORD 2020b). Rather than wait for stronger EJ guidelines from the EPA or the federal government, some states are moving ahead with EJ legislation of their own.

In order to address EJ concerns in CA, the state passed Assembly Bill 617 in 2017 (Garcia 2017). AB 617 takes a community-focused approach to combating air pollution in vulnerable neighborhoods by identifying regions with high cumulative exposure to air pollutants and empowering their local air district to build out local air quality testing capabilities and develop and execute a community emissions reduction plan (Garcia 2017). While still too early in its implementation for proper evaluation, $\mathrm{AB} 617$ has put a spotlight on EJ in CA and how it relates to local air quality testing and community involvement (Fowlie et al. 2020). PA could also consider taking a similar, state-level approach to protect overburdened communities from increased air pollution as the state joins RGGI.

\section{Political and legal status}

On October 3, 2019, Governor Tom Wolf signed an executive order (Wolf 2020) that required the Department of Environmental Protection (DEP) to develop a proposed rulemaking package to join RGGI and present it to the Environmental Quality Board (EQB). The Wolf administration claimed to have the authority to join RGGI under the Clean Air Act (Clean Air Act 1970), but many politicians viewed this action as executive overreach. In response, the PA General Assembly then passed House Bill 2025 (PA HB20205 2019) which stated that legislative approval is required to enact a price or fee on carbon, therefore effectively preventing the Wolf administration from joining RGGI unilaterally. The Governor vetoed this bill on September 24, 2020 (Wolf 2020), and the General Assembly did not have the required twothirds majority in each chamber to override the veto. Legal challenges to the regulation are also expected, but legal scholars anticipate the Governor's authority would be upheld (Morris 2020).
As it stands, the DEP is expected to submit the final regulation to the EQB and Independent Regulatory Review Commission for approval by the end of 2021, and Pennsylvania is on track to join RGGI in 2022. While participating in this regional cap-and-trade system will benefit PA air quality through the reductions of $\mathrm{CO}_{2}$ emissions and increased revenue for the Clean Air Fund, the regulation currently does not include language to mitigate any adverse impacts on vulnerable communities that could arise from the program. It is urgent to take protective measures to address the potential EJ concerns while the final regulations are still malleable.

\section{Policy options}

The following policy options focus on 25 PA Code Chapter 145 Section 306, which establishes standard requirements for the $\mathrm{CO}_{2}$ Budget Trading Program.

\section{i. Option 1: No changes to proposed rulemaking}

$\S 145.306$ would be implemented as currently drafted in the proposed regulation, without any revisions.

\section{Advantages}

Not having additional reporting requirements reduces the regulatory burden on emitters and the administrative responsibilities of the DEP. This could translate into money saved for both investors and taxpayers. Less regulatory oversight and market intervention could also allow $\mathrm{CO}_{2}$ credits to be traded more freely, so that the carbon market can run efficiently and generate the lowest prices.

\section{Disadvantages}

Neglecting to require any assessment of the impacts of the cap-and-trade program on air quality fails to address the potential EJ issues caused by this regulation. Marginalized communities could experience increased air pollution without a method to identify and rectify the situation built into the regulatory infrastructure. This could result in detrimental and long-term effects on public health.

\section{ii. Option 2: Annual air quality impact assessment using $\mathrm{CO}_{2}$ emissions data}

Amend $\$ 145.306$ to include an annual assessment determining whether any regions are disproportionately affected by increased air pollution as a result of the cap-and-trade program. The DEP would use the $\mathrm{CO}_{2}$ emissions measurements recorded and reported to them by existing procedures to 
assess these impacts and publish their findings to the public. This approach is already being considered by the DEP following a public comment period (McDonnell 2021).

\section{Advantages}

This reporting requirement would help address the EJ concerns of RGGI by monitoring its impact on an annual basis. If alarming trends do arise, the public would be aware of the issue and remedial action could be taken. This option would use the $\mathrm{CO}_{2}$ emissions data that is already being reported in the proposed rulemaking, so the additional regulatory burden on emitters would be minimal. $\mathrm{CO}_{2}$ is wellcorrelated with other harmful pollutants so the report would be based on a descriptive, yet coarse, data set (Cushing et al. 2018; Ostro et al. 2006; Burney 2020).

\section{Disadvantages}

This annual report would increase the administrative responsibilities of the DEP, which would demand more government resources to complete. It also increases the likelihood of market intervention, which could result in the carbon market underperforming economic theory and modeling (PA DEQ 2020). Furthermore, only using $\mathrm{CO}_{2}$ emissions data from the budget sources may not adequately resolve the real effects of air pollution on surrounding communities.

\section{iii. Option 3: Annual air quality impact assessment with expanded testing}

Amend \$145.306 to include the annual assessment from Option 2, with the additional requirement that the DEP identify a selection of overburdened communities and facilitate local air quality testing of co-pollutants in those communities to supplement the $\mathrm{CO}_{2}$ emissions data.

\section{Advantages}

In addition to the advantages of the annual air quality

\section{References}

Abelsohn, Alan, and Dave M. Stieb. 2011. "Health Effects of Outdoor Air Pollution." Canadian Family Physician 57 (8): 881-87. impact assessment discussed in Option 2, the local air quality monitoring in pre-selected, vulnerable areas will allow for improved spatial resolution and accuracy in the determination of air quality near RGGI-regulated facilities. This policy option incorporates aspects of CA's AB 617 to better inform the DEP on remedial modifications to the cap-andtrade policy, if necessary. Low-cost (Caubel et al. 2019; Lin et al. 2020) or mobile air quality sensors (Apte et al. 2017) and the leveraging of citizen scientists (Commodore et al. 2017) make execution of this plan more realistic than in the past. These local testing efforts can be funded by EPA innovation project grants or RGGI auction proceeds since each state has discretion over its own program revenue (RGGI 2020).

\section{Disadvantages}

Potential government intervention in the carbon market could have unintended consequences, as already mentioned in the disadvantages of Option 2 . The additional regulation of identifying vulnerable areas and implementing local air quality monitoring would further increase the administrative responsibilities of the DEP and demands on government resources. Lastly, many view local air pollution and climate change mitigation as two separate problems that could both be better served by their own policy approaches (Fowlie et al. 2020).

\section{Policy recommendation}

We recommend that the Department of Environmental Protection incorporate Option 3 into the final rulemaking of their $\mathrm{CO}_{2}$ Budget Trading Program (25 PA. CODE CH. 145). Pennsylvania's imminent entry into the Regional Greenhouse Gas Initiative poses a risk to the health of Environmental Justice communities in the state. Now is the time to incorporate meaningful safeguards for the most vulnerable populations in PA and set an example for other RGGI states.

Apte, Joshua S., Kyle P. Messier, Shahzad Gani, Michael Brauer, Thomas W. Kirchstetter, Melissa M. Lunden, Julian D. Marshall, Christopher J. Portier, Roel C.H. Vermeulen, and Steven P. Hamburg. 2017. "High-Resolution Air Pollution Mapping with Google Street View Cars: Exploiting Big Data." Environmental Science \& Technology 51 (12): 6999-7008. https://doi.org/10.1021/acs.est.7b00891 
Backes, Carl H., Timothy Nelin, Matthew W. Gorr, and Loren E. Wold. 2013. "Early Life Exposure to Air Pollution: How Bad Is It?" Toxicology Letters 216 47-53.

https://doi.org/10.1016/j.toxlet.2012.11.007

Burney, Jennifer A. 2020. "The Downstream Air Pollution Impacts of the Transition from Coal to Natural Gas in the United States." Nature Sustainability 3 (2). Nature Publishing Group: 152-60. https://doi.org/10.1038/s41893-019-0453-5.

California EPA, 2017. "Tracking and Evaluation of Benefits and Impacts of Greenhouse Gas Limits in Disadvantaged Communities: Initial Report." California EPA: Office of Environmental Health Hazard Assessment.

California Air Resource Board (CARB), 2019. "California Greenhouse Gas Emissions for 2000 to 2017 Trends of Emissions and Other Indicators." 2019. https://ww3.arb.ca.gov/cc/inventory/pubs/repo rts/2000 2016/ghg inventory trends 00-16.pdf

Carlson, Ann E. 2018. "THE CLEAN AIR ACT'S BLIND SPOT: MICROCLIMATES AND HOTSPOT POLLUTION." U.C.L.A. Law Review, 54.

Caubel, Julien J., Troy E. Cados, Chelsea V. Preble, and Thomas W. Kirchstetter. 2019. “A Distributed Network of 100 Black Carbon Sensors for 100 Days of Air Quality Monitoring in West Oakland, California." Environmental Science \& Technology 53 (13): 7564-73.

https://doi.org/10.1021/acs.est.9b00282

Chan, Nathan W., and John W. Morrow. 2019. "Unintended Consequences of Cap-and-Trade? Evidence from the Regional Greenhouse Gas Initiative." Energy Economics 80 (May): 411-22.

https://doi.org/10.1016/i.eneco.2019.01.007

Clean Air Act. 1970.

Clean Air Council, n.d., https://cleanair.org/public-health/pittsburghair-pollution/

Code of Federal Regulations (CFR), Title 40: Protection of the Environment, Part 50: National Primary and Secondary Ambient Qir Quality Standards, https://www.ecfr.gov/cgi-bin/textidx?SID=a504ed4b74811c80863d1ed5ccdb4934 \&mc=true\&tpl=/ecfrbrowse/Title40/40cfr50 ma in 02.tpl

Commodore, Adwoa, Sacoby Wilson, Omar Muhammad, Erik Svendsen, and John Pearce. 2017. "Community-Based Participatory Research for the Study of Air Pollution: A Review of Motivations, Approaches, and Outcomes." Environmental Monitoring and Assessment 189 (8): 378. https://doi.org/10.1007/s10661-017-6063-7
Cushing, Lara, Dan Blaustein-Rejto, Madeline Wander, Manuel Pastor, James Sadd, Allen Zhu, and Rachel Morello-Frosch. 2018. "Carbon Trading, CoPollutants, and Environmental Equity: Evidence from California's Cap-and-Trade Program (20112015)." PLOS Medicine 15 (7). Public Library of Science: e1002604.

https://doi.org/10.1371/journal.pmed.1002604

Di, Qian, Lingzhen Dai, Yun Wang, Antonella Zanobetti, Christine Choirat, Joel D. Schwartz, and Francesca Dominici. 2017. "Association of Short-Term Exposure to Air Pollution with Mortality in Older Adults." JAMA 318 (24): 2446.

https://doi.org/10.1001/jama.2017.17923

Food and Water Watch (FWW), 2021. "Cap and Trade: More Pollution for the Poor and People of Color." 2021.

https://foodandwaterwatch.org/wpcontent/uploads/2021/03/ib 1911 rggicaptrade ej-web.pdf

Fowlie, Meredith, Edward Rubin, and Reed Walker. 2019. "Bringing Satellite-Based Air Quality Estimates down to Earth." AEA Papers and Proceedings 109 (May): 283-88. https://doi.org/10.1257/pandp.20191064

Fowlie, Meredith, Reed Walker, and David Wooley. 2020 "Climate Policy, Environmental Justice, and Local Air Pollution." Brookings Institution.

Garcia, Cristina. 2017. CA Assembly Bill 617

Hernandez-Cortes, Danae, and Kyle Meng. 2020. "Do Environmental Markets Cause Environmental Injustice? Evidence from California's Carbon Market." w27205. Cambridge, MA: National Bureau of Economic Research. https://doi.org/10.3386/w27205

Hsiang, Solomon, Paulina Oliva, and Reed Walker. 2019. "The Distribution of Environmental Damages." Review of Environmental Economics and Policy 13 (1): 83-103. https://doi.org/10.1093/reep/rey024.

Lin, Yuan-Chien, Wan-Ju Chi, and Yong-Qing Lin. 2020. "The Improvement of Spatial-Temporal Resolution of Pm2.5 Estimation Based on MicroAir Quality Sensors by Using Data Fusion Technique." Environment International 134 (January): 105305. https://doi.org/10.1016/i.envint.2019.105305

Mcdonnell, Patrick. 2021. Interstate Pollution Transport Reduction Subchapter E. CO2 Budget Trading Program.

https://files.dep.state.pa.us/Air/AirQuality/AQP ortalFiles/Advisory\%20Committees/Air\%20Qua lity $\% 20$ Technical\%20Advisory $\% 20$ Committee $/ 2$ 021/4-821/FINAL AQTAC PA CO2 Budget Trading_Prog ram.pdf 
McKeown, Megan. 2020. “Carbon Trading \& Environmental Equity: Evidence from the Regional Greenhouse Gas Initiative (2000 - 2019)." PhD thesis, University of Washington.

Miranda, Marie Lynn, Sharon E. Edwards, Martha H. Keating, and Christopher J. Paul. 2011. "Making the Environmental Justice Grade: The Relative Burden of Air Pollution Exposure in the United States." International Journal of Environmental Research and Public Health 8 (6). Molecular Diversity Preservation International: 1755-71. https://doi.org/10.3390/ijerph8061755

Morris, Jackson. 2020. "Yes, the PA DEP Has Legal Authority to Do a RGGI Rule." National Resources Defense Council.

https://www.nrdc.org/experts/jacksonmorris/yes-pa-dep-has-legal-authority-do-rggi$\underline{\text { rule }}$

Ostro, Bart, Rachel Broadwin, Shelley Green, Wen-Ying Feng, and Michael Lipsett. 2006. "Fine Particulate Air Pollution and Mortality in Nine California Counties: Results from CALFINE." Environmental Health Perspectives 114 (1): 29-33. https://doi.org/10.1289/ehp.8335

Pennsylvania Department of Environmental Quality (PA DEQ) 2020. "Pennsylvania RGGI Modeling Report." https://files.dep.state.pa.us/Air/AirQuality/AQP ortalFiles/RGGI/PA RGGI Modeling_Report.pdf

Regional Greenhouse Gas Initiative (RGGI), 2019. “2017 Monitoring Report." $\mathrm{CO} 2$ Emissions from Electricity Generation and Imports in the Regional Greenhouse Gas Initiative. 2017 Regional Greenhouse Gas Initiative.

https://www.rggi.org/sites/default/files/Upload s/Electricity-Monitoring-

Reports/2017 Elec Monitoring Report.pdf

Regional Greenhouse Gas Initiative (RGGI) 2020 "Investment of RGGI Proceeds in 2018." https://www.rggi.org/sites/default/files/Upload s/Proceeds/RGGI Proceeds Report 2018.pdf

Smith, Kirk R., Howard Frumkin, Kalpana Balakrishnan, Colin D. Butler, Zoë A. Chafe, Ian Fairlie, Patrick Kinney, et al. 2013. "Energy and Human Health." Annual Review of Public Health 34 (1): 159-88. https://doi.org/10.1146/annurev-publhealth$\underline{031912-114404}$

Snyder, Emily G., Timothy H. Watkins, Paul A. Solomon, Eben D. Thoma, Ronald W. Williams, Gayle S. W. Hagler, David Shelow, David A. Hindin, Vasu J. Kilaru, and Peter W. Preuss. 2013. "The Changing Paradigm of Air Pollution Monitoring." Environmental Science \& Technology 47 (20). American Chemical Society: 11369-77. https://doi.org/10.1021/es4022602
Solomon, Paul A., Maria Costantini, Thomas J. Grahame, Miriam E. Gerlofs-Nijland, Flemming R. Cassee, Armistead G. Russell, Jeffrey R. Brook, et al. 2012. "Air Pollution and Health: Bridging the Gap from Sources to Health Outcomes: Conference Summary." Air Quality, Atmosphere \& Health 5 (1): 9-62. https://doi.org/10.1007/s11869-011-0161-4

Struzzi. n.d. "HB2025."

Tung, Elizabeth L., Kathleen A. Cagney, Monica E. Peek, and Marshall H. Chin. 2017. "Spatial Context and Health Inequity: Reconfiguring Race, Place, and Poverty." Journal of Urban Health: Bulletin of the New York Academy of Medicine 94 (6): 757-63. https://doi.org/10.1007/s11524-017-0210-x

United States Environmental Protection Agency (US EPA) 2021, "EPA Annual Environmental Justice Progress Report Fy2020"

United States Environmental Protection Agency (US EPA) OP. 2016. "EJ 2020 Glossary." Data and Tools. US EPA.

https://www.epa.gov/environmentaljustice/ej2020-glossary

United States Environmental Protection Agency Office of Research and Development (US EPA ORD). 2020a "2020 Regional-State-Tribal Innovation Projects." Collections and Lists. US EPA. https://www.epa.gov/innovation/2020regional-state-tribal-innovation-projects

United States Environmental Protection Agency Office of Research and Development (US EPA ORD) 2020b. "Region 2: Evaluating Air Pollution Sensors for Hot Spot Monitoring by Citizen Scientists." Overviews and Factsheets. US EPA.

https://www.epa.gov/innovation/region-2evaluating-air-pollution-sensors-hot-spotmonitoring-citizen-scientists

Wellbery, Caroline. 2017. "The Health Hazards of Air Pollution Implications for Your Patients." American Family Physician 95 (3): 3.

Wolf, Tom. 2020 "SB2025 Veto Message."

Wolf, Tom, and Patrick McDonnell. 2020. "Commonwealth of Pennsylvania Department of Environmental Protection 2020 Annual Ambient Air Monitoring Network Plan," 155.

Wu, X., R. C. Nethery, M. B. Sabath, D. Braun, and F. Dominici. 2020. "Air Pollution and COVID-19 Mortality in the United States: Strengths and Limitations of an Ecological Regression Analysis." Science Advances 6 (45): eabd4049. https://doi.org/10.1126/sciadv.abd4049 
Ryan Chaban received his B.S.E in Engineering Physics from Case Western Reserve University and is pursuing his Ph.D. in Physics at William \& Mary where he studies nuclear fusion science on the DIII-D tokamak in San Diego, CA. During the summer of 2020, as an inaugural Commonwealth of Virginia Engineering \& Science (COVES) Fellow he researched controlled environment agriculture and carbon pricing for Dominion Energy. After graduating, he hopes to use his research skillset to address energy and climate issues through data driven insights.

Daniel Dudt is a Ph.D. candidate in the Mechanical and Aerospace Engineering department at Princeton University, where he is also pursuing certificates in Computational Science and Engineering and in Science, Technology and Environmental Policy. Through his research, Daniel develops advanced computational tools to improve stellarators for controlled fusion energy. He holds a B.S. in Mechanical Engineering from Bucknell University with minors in Mathematics and Physics.

Bethany Gordon received her bachelor's degree in civil and environmental engineering in 2017 from the University of Virginia (UVA), where she is currently a Ph.D. candidate in civil and environmental engineering. As an equity-driven engineer, Bethany utilizes behavioral science and social psychology to improve social justice in design of the built environment. She is a 2021 Christine Mirzayan Science Technology \& Policy Fellow, a 2019 recipient of an NSF Graduate Research Fellowship, the first-place winner in the How to Change the World International Podcast Competition (2017) and was appointed to the National Executive Board of 500 Women Scientists (2019).

Evan Ostrowski is a Ph.D. candidate at Princeton University in the Chemical and Biological Engineering Department and received his bachelor's degree in chemical and biomolecular engineering from Case Western Reserve University. He utilizes experimental surface science techniques to investigate plasma-material interactions and advance the field of fusion energy. Evan is passionate about clean energy solutions and including more scientists in the policymaking process.

\section{Disclaimer}

The authors declare no conflicts of interest. 